\title{
Positive and Negative Motivation in Nucleus Accumbens Shell: Bivalent Rostrocaudal Gradients for GABA-Elicited Eating, Taste "Liking"/"Disliking" Reactions, Place Preference/Avoidance, and Fear
}

\author{
Sheila M. Reynolds and Kent C. Berridge \\ Department of Psychology, University of Michigan, Ann Arbor, Michigan 48109-1109
}

\begin{abstract}
Microinjection of the $\mathrm{GABA}_{\mathrm{A}}$ agonist muscimol in the rostral medial accumbens shell in rats elicits appetitive eating behavior, but in the caudal shell instead elicits fearful defensive treading behavior. To further test the hypothesis that rostral shell muscimol microinjections produce positive motivational states, whereas caudal shell muscimol produces negative states, we measured behavioral place preference/avoidance conditioning and affective hedonic and aversive orofacial expressions of taste-elicited "liking" and "disliking" (gapes, etc.) in addition to fear and feeding behaviors. Farthest rostral muscimol microinjections (75 ng) caused increased eating behavior and also caused positive conditioned place preferences and increased positive hedonic reactions to the taste of sucrose. By contrast, caudal shell microinjections elicited negative defensive treading and caused robust negative conditioned place
\end{abstract}

avoidance and negative aversive reactions to sucrose or quinine tastes. Intermediate rostral microinjections elicited effects of mixed positive/negative valence (positive appetitive eating behavior but negative place avoidance and negative taste reactions at mid-rostral sites, and sometimes positive eating simultaneously with fearful defensive treading more caudally). These results indicate that GABAergic neurotransmission in local microcircuits in nucleus accumbens mediates motivated/ affective behavior that is bivalently organized along rostrocaudal gradients.

Key words: accumbens shell; GABA; food intake; reward; appetite; ingestive behavior; motivation; glutamate; mesolimbic; extended amygdala; pallidal; dopamine; glutamate; fear; defense; muscimol; microinjection; taste; palatability; pleasure; affect; aversion
How do positive and negative motivational functions of the nucleus accumbens relate to each other? Mapping of motivational valence in accumbens is a major puzzle for contemporary affective neuroscience. Mesolimbic systems are widely thought to be involved in both positive (appetitive/reward) and negative (stress/ defense) motivational functions (Koob and Bloom, 1988; Salamone, 1994; Wise, 1998; Berridge et al., 1999; Gray et al., 1999; Kelley, 1999; McBride et al., 1999; Horvitz, 2000). However, most analyses have focused either on only one or the other motivational valence or on general functions such as attention or sensorimotor activation. Mechanisms by which mesolimbic systems distinguish between positive and negative valence have remained unclear. A more systematic understanding is needed of how positive valence versus negative valence is organized in accumbens microcircuits.

Recent studies suggest that GABAergic neurotransmission in medial accumbens shell might map positive/negative motivational functions along a rostrocaudal gradient. Eating behavior and food intake, often regarded as appetitive or positively motivated, are increased in rats by rostral shell microinjections of a $\mathrm{GABA}_{\mathrm{A}}$

Received Jan. 10, 2002; revised May 28, 2002; accepted June 5, 2002.

This research was supported by a National Science Foundation grant (IBN 9604408) to K.C.B. and a National Institutes of Health fellowship (National Institute on Drug Abuse F31 DA14679-01) and training grant (National Institute on Deafness and Other Communication Disorders T32 DC00011) to S.M.R. We thank Prof. Craig W. Berridge and Prof. Ann E. Kelley for helpful comments on earlier versions of this manuscript.

Correspondence should be addressed to Sheila M. Reynolds, Department of Psychology, University of Michigan, Ann Arbor, MI 48109-1109. E-mail: sheilar@umich.edu or berridge@umich.edu.

Copyright (ㄷ) 2002 Society for Neuroscience $\quad 0270-6474 / 02 / 227308-12 \$ 15.00 / 0$ agonist (Stratford and Kelley, 1997; Basso and Kelley, 1999; Reynolds and Berridge, 2001), which may hyperpolarize medium spiny neurons primarily via postsynaptic receptors (Waldvogel et al., 1997, 1998; Fujiyama et al., 2000; Schwarzer et al., 2001). $\mathrm{GABA}_{\mathrm{B}}$ agonists and glutamate antagonists produce similar appetitive effects at the same sites (Maldonado-Irizarry et al., 1995; Kelley and Swanson, 1997; Stratford and Kelley, 1997; Stratford et al., 1998). By contrast, in caudal shell, GABAergic activation elicits fearful defensive treading behavior (Reynolds and Berridge, 2001), a species-specific defense reaction (Bolles, 1970) naturally used by mice, ground squirrels, and rats as an antipredator response against scorpions, rattlesnakes, and other noxious stimuli (Owings and Coss, 1977; Wilkie et al., 1979; Londei et al., 1998; Owings and Morton, 1998).

The rostrocaudal segregation of feeding versus fearful behaviors in medial shell after $\mathrm{GABA}_{\mathrm{A}}$ agonist microinjections suggests that the accumbens shell contains multiple functional microcircuits (Pennartz et al., 1994; O’Donnell, 1999), which may be distributed rostrocaudally to modulate motivational valence. Does rostral shell muscimol produce positive motivational states, whereas caudal shell muscimol produces negative states? If so, then other types of motivated behavior ought to be modulated in the same bivalent manner as fear and feeding.

The conditioned place preference/avoidance paradigm is a traditional measure of both reward and aversive properties of drugs (Tzschentke, 1998; Bardo and Bevins, 2000). It can assess whether accumbens microinjections cause conditioned preference or avoidance of associated place contexts (Shippenberg et al., 1991; Liao et al., 2000). The affective taste reactivity paradigm is 
a more novel behavioral assay for specifically measuring hedonic impact (Berridge, 2000). Sweet and bitter tastes elicit valenced behavioral facial reactions, which are homologous in human infants, nonhuman primates, and even rats (Steiner, 1973; Grill and Norgren, 1978; Berridge, 2000; Steiner et al., 2001). Taste reactivity patterns provide behavioral indicators of positive/negative affective evaluations of tastes (i.e., "liking" or "disliking") and so can be used for objective examination of brain mechanisms of valenced affective reactions, without requiring knowledge about unobservable subjective states (Berridge and Winkielman, 2002). For example, previous taste reactivity studies have identified accumbens opioid neurotransmission and related pallidal circuits as causes for increased positive hedonic impact or as necessary for normal hedonic impact (Cromwell and Berridge, 1993; Peciña and Berridge, 2000; Soderpalm and Berridge, 2000).

In this study we tested whether rostrocaudal gradients exist in accumbens shell for motivational/affective valence produced by muscimol microinjections. We found that GABA receptor activation in far rostral shell increased positive eating, place preference, and positive hedonic reactions to sucrose taste ("liking"). Conversely, caudal muscimol microinjections caused negative fearful behavior, conditioned avoidance, and negative affective reactions to taste. Intermediate shell GABAergic activation produced combined positive and negative motivational effects. These observations support the hypothesis that GABAergic modulation of microcircuits in accumbens shell globally generates bivalent motivational functions along rostrocaudal gradients.

\section{MATERIALS AND METHODS}

General design. This study compared the effects of shell GABAergic activation on four types of motivated or affective behaviors (feeding behavior, defensive treading behavior, conditioned place preference/ avoidance, and positive/negative affective reactions to tastes). To limit the number of microinjections required per rat, this was done in two separate experiments. In experiment 1 , muscimol-elicited place preference/avoidance conditioning was compared with fear and feeding behavior elicited by microinjections at the same site on a within-subject basis. In experiment 2 the effects of muscimol microinjection on affective taste reactivity patterns elicited by oral infusions of sucrose or quinine were compared with fear versus feeding elicited at the same microinjection sites.

Subjects. Eighty-six male and female Sprague Dawley rats (280-320 gm at the time of surgery) were group housed $\left(\sim 21^{\circ} \mathrm{C} ; 12 \mathrm{hr}\right.$ light/dark cycle $)$ with ad libitum food (Purina Rat Chow) and water (tap water).

Microinjection cannula surgery. Rats were pretreated with $0.1 \mathrm{ml}$ of atropine sulfate and anesthetized with a mixture of ketamine $\mathrm{HCl}(80$ $\mathrm{mg} / \mathrm{kg}$, i.p.) and xylazine $(5 \mathrm{mg} / \mathrm{kg})$. The stereotaxic incisor bar was set at $5.0 \mathrm{~mm}$ above interaural zero to achieve a slanted cannula angle and avoid penetrating the lateral ventricles. Chronic microinjection guide cannulas (23 gauge) were implanted bilaterally $2 \mathrm{~mm}$ above rostral or caudal sites in the medial nucleus accumbens shell. Coordinates for rostral versus caudal shell sites were chosen from our earlier study (Reynolds and Berridge, 2001) on the basis of the capacity of rostral sites to maximally evoke appetitive eating behavior after muscimol microinjection and of caudal sites to maximally evoke defensive treading behavior. Forty-one rats received cannulas targeted in the rostral half of the accumbens shell [targeted at anteroposterior (AP) +3.1-3.3, mediolateral (ML) \pm 0.8 , dorsoventral (DV) -5.7$]$, and 33 rats received cannulas targeted in the caudal shell half ( $\mathrm{AP}+2.1, \mathrm{ML} \pm 1.2, \mathrm{DV}-5.5)$, although actual placements of both groups also included some rats with intermediate sites. An additional 12 rats received cannulas targeted outside the nucleus accumbens, in the rostral or caudal neostriatum or in the septum at least $1 \mathrm{~mm}$ dorsal to the nucleus accumbens, as an anatomical control group. The guide cannulas for extra-accumbens placements made trajectories through the neocortex similar to cannulas for accumbens sites. Microinjection cannulas were anchored to the skull with screws and acrylic cement. A stainless steel obturator was inserted into each microinjection guide cannula to help prevent occlusions. Each rat received prophylactic penicillin (aquacillin; 45,000 U, i.m.) after surgery. At least $7 \mathrm{~d}$ were allowed for recovery before behavioral testing.

Oral cannula surgery (for taste reactivity test). A subgroup of 32 rats (16 with rostral shell sites; 16 with caudal shell) were also implanted in the same surgery with bilateral oral cannulas to permit taste reactivity tests, which require the direct infusion of taste solutions into the mouth. Oral cannulas (heat-flared polyethylene-100 tubing) entered the mouth just lateral to the first maxillary molar, ascended lateral to the skull, and exited the head at the dorsal skull, where they were attached to 19 gauge steel tubing. All cannulas were anchored to the skull with screws and acrylic cement. Each rat received prophylactic penicillin (aquacillin; $45,000 \mathrm{U}$, i.m.) after surgery and every $2 \mathrm{~d}$ for $\sim 1$ week. At least $14 \mathrm{~d}$ were allowed for recovery after surgery before behavioral testing.

Drugs and intracerebral microinjections. Muscimol (Sigma, St. Louis, MO) was dissolved in sterile $0.15 \mathrm{~m}$ saline, which was also used for vehicle control microinjections $(0.5 \mu \mathrm{l})$. We chose the muscimol dose (75 ng per side, resulting in a total dose of $150 \mathrm{ng}$ ) that elicited maximum eating behavior when administered in rostral accumbens shell in our previous study and that also elicited substantial defensive treading behavior when administered in caudal shell (Reynolds and Berridge, 2001). Microinjection cannulas ( 29 gauge) extended $2.0 \mathrm{~mm}$ beyond the ventral tip of the guide and were attached to a syringe pump via PE-20 tubing. The rats were gently handheld while they were bilaterally infused with a microinjection volume of $0.5 \mu \mathrm{l}$ at a rate of $0.30 \mu \mathrm{l} / \mathrm{min}$ (either vehicle or muscimol, counterbalanced within-subject design). After infusion, the injectors remained in place for an additional $1 \mathrm{~min}$ to allow for drug diffusion before their withdrawal and replacement of the obturators. Each rat was placed in the chamber for behavioral testing immediately after microinjection. Muscimol and vehicle microinjections were spaced $48 \mathrm{hr}$ apart, in counterbalanced order across rats.

Behavioral eating/defensive treading tests. The ability of muscimol to elicit appetitive eating behavior and defensive treading behavior was assessed simultaneously in the same test procedure (Reynolds and Berridge, 2001). Rats were habituated to test chambers for 4 consecutive days before the beginning of behavioral testing and received a vehicle microinjection on the final day of habituation. The transparent test chambers $(23 \times 20 \times 45 \mathrm{~cm})$ contained both pre-weighed food $(\sim 20 \mathrm{gm}$ chow pellets), which could support eating behavior, and wood shavings spread $2.0 \mathrm{~cm}$ in depth across the chamber floor, which could support defensive treading behavior and be used by the rat during treading to construct defensive mounds (typically placed in front of the wall that faced the experimenter, or less commonly in corners). Water was also available ad libitum during each $60 \mathrm{~min}$ test session. The behavior of each rat was videotaped for later off-line detailed analysis of eating behavior and defensive treading behavior. After each test, the bedding and floor of the cage beneath the food source were inspected, and any food crumbs were separated. That check never revealed more than minimal dusting of crumbs $(<0.5 \mathrm{gm})$, indicating that our food intake measure reflected real consumption (verified also by video scoring of time spent in eating behavior).

Video scoring of eating/defensive treading. The videotapes were scored by an experimenter who was blind to drug treatment. Behavior was analyzed for time spent eating and time spent defensive treading (both measured in seconds; intake was also measured as grams of food consumed).

Histology. Rats were deeply anesthetized with sodium pentobarbital at the end of the experiment, given microinjections of ink for anatomical localization of cannula sites $(0.5 \mu \mathrm{l})$, and perfused transcardially with buffered saline, followed by $4 \%$ paraformaldehyde solution. Their brains were removed, postfixed, sectioned $(40 \mu \mathrm{m})$, mounted on slides, and stained with cresyl violet. Cannula placements were mapped onto a stereotaxic atlas (Paxinos and Watson, 1997) and confirmed to be in the accumbens shell or, for the anatomical control group, the septum or rostral or caudal neostriatum.

Construction of functional maps. To construct anatomical maps of functional localization within the accumbens shell, functional criteria were set to record the significant occurrence of each of the five types of motivated behavior (eating, defensive treading, place conditioning, hedonic reactions to sucrose, aversive reactions to quinine). Muscimol microinjection sites that met the criteria described below were plotted on digitized stereotaxic atlas maps that depicted the intensity of behavior elicited at various shell sites.

Eating: mapping criterion. A rat was classified as an eater if muscimol microinjection caused it to eat $>200 \%$ of the amount of food it ate after vehicle microinjection and spent $>200 \%$ more time engaged in eating 
behavior (Reynolds and Berridge, 2001). Symbols representing the percentage change in food intake for each rat were mapped onto its microinjection cannula sites in the stereotaxic atlas.

Defensive treading: mapping criterion. A rat was classified as a defensive treader if it emitted at least $100 \mathrm{sec}$ of cumulative defensive treading behavior after muscimol microinjection (rats generally emitted zero defensive treading after vehicle microinjections). A defensive treading score was calculated for each rat and mapped onto its microinjection cannula sites in the stereotaxic atlas.

Note: If a rat met criteria for both defensive treading and eating, it was classified as both. Animals that met neither criterion were classified as negative for these behaviors.

Place conditioning: mapping of preference versus avoidance. Place conditioning scoring procedures corrected for initial place biases by dividing the time a rat spent in its muscimol-paired chamber during test by the mean time spent in that same chamber by all rats across all treatments. The result was expressed as a percentage score, which could be either positive (conditioned place preference) or negative (conditioned place avoidance). Place preference or avoidance scores were calculated for each rat and mapped onto its microinjection cannula sites using a stereotaxic atlas.

For the purpose of quantifying place conditioning results in the final map, each microinjection site was assigned to one of the following categories: more than $+20 \%$ increase in place preference after pairings with muscimol (compared with vehicle microinjection at the same site), $>10 \%$ preference, no change in place preference/avoidance (less than +9 to $-9 \%$ change), more than $-10 \%$ avoidance after pairing with muscimol, or more than $-25 \%$ avoidance after pairing with muscimol.

Taste reactivity: mapping of positive hedonic enhancement. Positive affective taste reactions normally elicited by sucrose infusions were totaled separately for each rat (Berridge, 2000). To assess muscimol effects, positive hedonic reactions elicited by sucrose infusions after muscimol microinjections were divided by the same rat's total positive reactions elicited by sucrose after vehicle microinjections. Each hedonic percentage change score could be either positive (hedonic enhancement after muscimol) or negative (hedonic diminishment). A hedonic change score was plotted for each rat and mapped onto its microinjection cannula sites using a stereotaxic atlas. For mapping purposes, microinjection sites were assigned to one of the following categories: more than $+30 \%$ enhancement of hedonic reactions elicited by sucrose after muscimol compared with after vehicle microinjection, more than $+10 \%$ hedonic enhancement, no change (less than $\pm 9 \%$ change), more than $-10 \%$ suppression, or more than $-50 \%$ suppression of hedonic reactions.

Mapping of negative taste aversion. Affectively negative aversive reactions, best elicited by quinine taste, were similarly totaled separately after muscimol microinjections and compared with reactions after vehicle microinjections at the same site. The aversive percentage score could reflect an increase (more aversive after muscimol) or suppression (less aversive). An aversive change score was plotted for each rat and mapped onto its microinjection cannula sites according to the following criteria: more than $-50 \%$ decrease in aversive reactions after muscimol compared with vehicle microinjection, no change (less than $\pm 49 \%$ change), more than $+50 \%$ increase in aversive reactions, or more than $+200 \%$ increase in aversive reactions.

\section{Experiment 1: place preference/avoidance conditioning versus feeding/fear}

Experimental design. Forty-two rats ( 25 with cannula aimed at the rostral shell; 17 caudal shell) were trained and tested for place conditioning. One day after the place conditioning test, rats were also tested for muscimolelicited eating behavior and defensive treading behavior.

Place conditioning training procedure. Conditioned place preference/ avoidance training occurred in a three-compartment apparatus. Two large side chambers $(28 \times 21 \times 21 \mathrm{~cm})$ surrounded a smaller central compartment $(12 \times 21 \times 21 \mathrm{~cm})$. One side compartment was brightly lit and had black-colored walls and a wire grid floor. The other side compartment was darkened and had white walls and a wire mesh floor. Before this experiment, the effectiveness of our place conditioning procedure was confirmed using a separate group of rats, successfully conditioned to have a place preference for a compartment paired with diazepam administration ( $1 \mathrm{mg} / \mathrm{kg}$, i.p) (Spyraki et al., 1985).

Each rat was assigned in a counterbalanced manner to have one side compartment paired with muscimol microinjection. Rats received four consecutive daily conditioning trials containing two muscimol microin- jections paired with their assigned compartment (days 2 and 4) and two vehicle microinjections paired with the other compartment (days 1 and $3)$. Each day, rats received bilateral microinjections (0,75 ng muscimol in $0.5 \mu \mathrm{l}$ ) before immediately being placed in the appropriate side compartment, where they were confined for $30 \mathrm{~min}$.

Conditioned place preference/avoidance test. On the test day for conditioned preference/avoidance (day 5), rats were not given microinjections. Instead they were simply taken from the home cage and placed into the central compartment and allowed to freely explore the entire apparatus for $30 \mathrm{~min}$. Their location during test sessions was videotaped and scored for cumulative time (seconds) spent in each compartment (a rat was considered to be in a particular compartment whenever its head and both forelimbs were inside).

Statistical analysis. Effects of muscimol microinjections on conditioned place preference were examined initially by two-way ANOVA [DRUG (muscimol vs vehicle) $\times$ SITE (rostral versus caudal shell], and specific drug effects were further examined separately for each site by post hoc tests (Bonferroni). Effects of muscimol on food intake and defensive treading were also examined by ANOVA and post hoc tests. One rat from experiment 1 was excluded because of misplaced cannulas outside the shell. Two rats were excluded from the initial classification and place preference comparison of muscimol-elicited treaders versus eaters because muscimol elicited both behaviors from them, and it was important that rats be either predominantly appetitive or defensive for the purpose of comparing that valence with the valence of conditioned place preference/avoidance. However, microinjection sites from all accumbens rats are included in the functional maps of muscimol-elicited eating behavior and defensive behavior (see Figs. 1, 7, and 8).

\section{Experiment 2: affective positive/negative taste reactivity versus feeding/fear}

Taste reactivity test. Immediately after microinjection, each rat's oral cannula was connected to a stimulus delivery line (PE-50 tubing attached to a PE-10 nozzle), and the rat was placed into a transparent test chamber. A mirror positioned beneath the transparent floor reflected a view of the rat's face and mouth into the close-up lens of a video camera to permit videotaping of affective facial and body reactions to oral inf usions of sucrose or quinine taste stimuli. Solutions of either $0.1 \mathrm{M}$ sucrose or $3 \times 10^{-5} \mathrm{M}$ quinine $\mathrm{HCl}$ were infused into the rat's mouth through the oral cannula by a syringe pump over an exposure period of $1 \mathrm{~min}(1 \mathrm{ml} / 60 \mathrm{sec})$. Each rat received a $1 \mathrm{ml}$ intra-oral taste infusion of the same solution at three points in time: 10,30 , and 60 min after the microinjection (each test lasted $1 \mathrm{~min}$ ). Rats received only one taste (sucrose or quinine) per day, and the order of taste/drug testing was counterbalanced. Affective reactions elicited by the taste stimuli were videotaped for subsequent analysis. After-reactions that occurred within a $30 \mathrm{sec}$ interval after the end of the infusion were also recorded for separate scoring because a previous report suggested that after-reactions during the $30 \mathrm{sec}$ period after sucrose inf usions may be more sensitive to mild shifts in palatability than reactions that occur during oral infusions, because of release from response constraints imposed by the physical solution in the mouth (Grill et al., 1996).

Video scoring of taste reactivity. Several taste-elicited affective reactions of rats are homologous to affective facial reactions of human infants and of at least 11 great ape and monkey species, as indicated by microstructural features such as sharing of identical allometric equations to describe component speed and by taxonomic continuity across species in the number of shared components (Berridge, 2000; Steiner et al., 2001). Affective reaction patterns were scored in slow motion video analysis (1/30 sec frame-by-frame to $1 / 10$ actual speed). Positive hedonic reactions included rhythmic midline tongue protrusions, lateral tongue protrusions, and paw licking. Aversive reaction patterns included gapes, headshakes, forelimb flails, face washing, chin rubs, and paw treading. Neutral reactions (less strongly linked to hedonic/aversive evaluations) were rhythmic mouth movements and passive drip of the solution. To be sure that every component made an equal contribution to the final hedonic or aversive scores, reactions that occur in continuous bouts were scored in time bins (Berridge, 2000). Components characterized by bouts of moderate duration, such as rhythmic tongue protrusions, chin rubs, and paw treading, were scored in $2 \mathrm{sec}$ bins (continuous repetitions within $2 \mathrm{sec}$ scored as one occurrence). Components that typically have longer bout durations, such as paw licking, rhythmic mouth movements, passive drip, and face washing were similarly scored in $5 \mathrm{sec}$ bins. Other reactions that can occur as single behaviors were scored as separate occurrences (lateral tongue protrusions, gapes, headshakes, forelimb flails). These pro- 
cedures result in summation scores for hedonic versus aversive reactions, which equally represent all components within an affective category and are not biased by differences in relative baseline frequencies among components.

Eating/defensive treading test. Cumulative eating behavior and defensive treading behavior were measured at 10,30 , and $60 \mathrm{~min}$ after microinjection as described above. This allowed direct comparison at three time points of effects on eating behavior, treading behavior, and positive and negative affective taste reactivity patterns. The order of eating/defensive treading and taste reactivity tests was counterbalanced between rats.

Statistical analysis. Taste reactivity data were initially examined by repeated measures three-way ANOVA [drug (vehicle vs muscimol) $\times$ affective category (positive hedonic reactions vs neutral reactions vs negative aversive reactions] $\times$ time (at 10,30,60 min points after microinjection). Reactions to sucrose inf usions were analyzed separately from reactions to quinine. To further identify effects within particular affective categories (hedonic, neutral, aversive), the reaction totals of each category were analyzed separately by repeated measures two-way ANOVA (drug $\times$ time), followed by post hoc Bonferroni tests. Food intake, eating behavior duration, and defensive treading behavior duration were similarly analyzed by ANOVA and Bonferroni tests.

To detect whether accumbens microinjections had orofacial or forelimb motor effects that altered particular movement components involved in taste reactivity, all individual components (rhythmic tongue protrusion, gape, etc.) were finally examined separately by paired $t$ test (drug vs vehicle). A specific motor effect should alter only components involving particular types of movement (e.g., tongue extension), whereas a general motor arousal effect should alter all components together in both positive and negative affective reaction categories. By contrast, an affectively valenced effect of muscimol microinjection should alter the reaction components belonging to one affective category, but not those belonging to the opposite affective category. For example, increased liking (the neural evaluation of the stimulus that results in more positive behavioral response) should increase most reactions belonging to the positive hedonic category but not increase reactions belonging to neutral or aversive categories (Berridge, 2000).

Two rats were excluded from taste reactivity analysis because of misplaced microinjection cannulas; three additional rats with rostral microinjection placements were excluded because of failure to meet eating criteria, and one rat was excluded from taste reactivity analysis because it exhibited both eating and defensive treading behavior after muscimol microinjection.

\section{RESULTS}

\section{Experiment 1: place preference/avoidance conditioning versus feeding/fear}

\section{Muscimol-elicited feeding versus fear}

Muscimol microinjection into the rostral two-thirds of the accumbens shell (2.7-1.2 mm anterior to bregma) (Figs. 1, 7, 8) elicited robust increases in food intake: rats consumed $>400 \%$ more food than after vehicle microinjection [ANOVA (drug) $F_{(1,41)}=53.29$; $p<0.001]$ and spent $>500 \%$ more time in eating behavior [ANOVA (drug) $F_{(1,41)}=23.46 ; p<0.001$ ], consistent with previous reports (Stratford and Kelley, 1997; Basso and Kelley, 1999; Reynolds and Berridge, 2001). Little to no defensive treading behavior was elicited after rostral muscimol microinjections [only 10-20 sec cumulative duration during 60 min test session after muscimol microinjection versus $0-5 \mathrm{sec}$ after vehicle; ANOVA (drug) $F_{(1,41)}=9.65 ; p<0.01$ ], again consistent with our previous report (Reynolds and Berridge, 2001).

By contrast, muscimol microinjection into the caudal third of the accumbens shell (1.2-0.48 mm anterior to bregma) (Figs. 1, 7, 8 ) elicited strong defensive treading behavior, averaging $>300 \mathrm{sec}$ cumulative treading after muscimol [compared with virtually 0 sec after vehicle; ANOVA (drug) $\left.F_{(1,27)}=47.69 ; p<0.001\right]$. Mounds of wood shavings were typically constructed by this defensive treading behavior (10-20 cm length, 5-10 cm height and width) (Reynolds and Berridge, 2001). Mounds were most
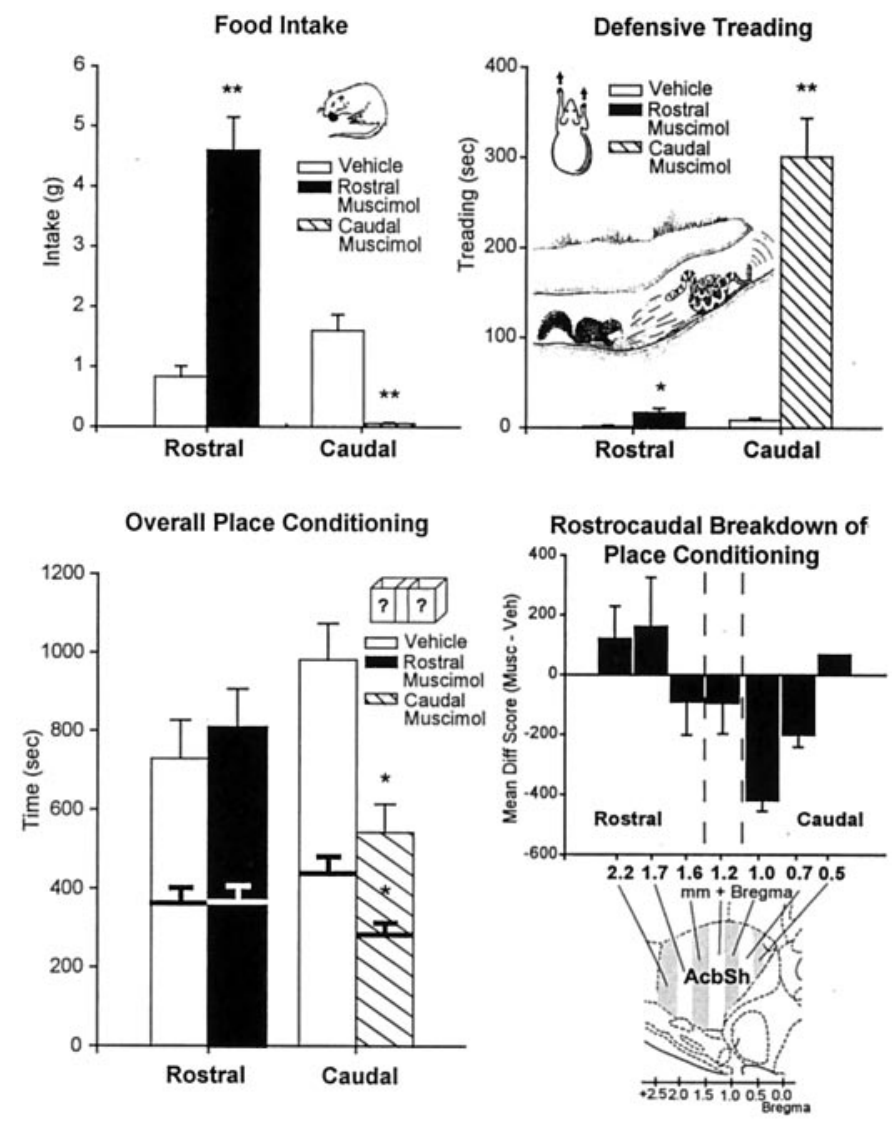

Figure 1. Experiment 1: food intake, defensive treading behavior, and place conditioning (mean \pm SEM) after vehicle or $75 \mathrm{ng}$ muscimol microinjection. Food Intake (top left), Rostral shell muscimol microinjection robustly increased food intake, whereas caudal muscimol strongly suppressed intake, compared with vehicle (cumulative grams of chow intake over $60 \mathrm{~min}$; results in terms of time spent eating were similar). Defensive Treading (top right), Caudal muscimol elicited robust defensive treading behavior, whereas rostral muscimol elicited minimal treading behavior (cumulative over $60 \mathrm{~min}$ ). Ground squirrel drawing depicts similar defensive treading behavior by Spermophilus beecheyi directed toward predatory rattlesnake [modified from Owings and Morton (1998)]. Overall Place Conditioning (bottom left), Conditioned place avoidance was produced by muscimol microinjection into caudal shell but mixed effects in the rostral shell (conditioned place preference at far rostral sites, but conditioned place avoidance at intermediate rostral sites; bars depict cumulative duration measured at $30 \mathrm{~min}$; bold lines within bars depict duration measured at $15 \mathrm{~min})$. Rostrocaudal Breakdown of Place Conditioning (bottom right), Positive-to-negative rostrocaudal gradient in conditioned place preference/avoidance was revealed by plotting preference separately for sites at each AP level. Statistical significance denoted by $* * p<0.001$ and $* p<0.05$ (muscimol compared with vehicle in each case).

often placed defensively between the rat and the transparent wall at the front of the cage that faced the experimenter, light source, and open room. In these same caudal sites, muscimol actually suppressed food intake below vehicle levels [ANOVA (drug) $\left.F_{(1,27)}=30.39 ; p<0.001\right)$ instead of increasing eating behavior. In addition, when the experimenter gently tried to retrieve the rat at the end of the trial, rats often emitted distress vocalizations and strong behavioral attempts to escape if they had earlier received caudal muscimol and had emitted defensive treading behavior. By contrast, fearful escape attempts and distress vocalizations were generally not observed after caudal microinjection of vehicle, nor were they observed in rats that received rostral injections of 
muscimol or vehicle. All of these shell effects on defensive behaviors and eating behavior were similar to those that we reported before (Reynolds and Berridge, 2001). By comparison, muscimol in neostriatal or septal sites dorsal to the accumbens shell did not elicit either defensive treading or eating behavior. Food intake was not increased at these sites by muscimol (oneway repeated measures ANOVA $F_{(1,11)}=1.75 ; p=0.24$; rostral neostriatum vehicle $=0.72 \pm 0.39 \mathrm{gm}$, muscimol $=1.28 \pm 0.63$ gm; intermediate neostriatum and lateral septum vehicle $=$ $1.73 \pm 0.70 \mathrm{gm}$, muscimol $=0.92 \pm 0.49 \mathrm{gm})$, nor was defensive treading behavior reliably elicited by muscimol in dorsal structures outside of the nucleus accumbens (ANOVA $F_{(1,11)}=1.46$; $p=0.28$; rostral neostriatum: vehicle $=4.17 \pm 1.91$ sec, muscimol $=3.50 \pm 1.26 \mathrm{sec}$; intermediate neostriatum and lateral septum: vehicle $=4.67 \pm 1.61 \mathrm{sec}$, muscimol $=48.50 \pm 35.71 \mathrm{sec})$. Robust defensive treading $(>200 \mathrm{sec})$ was observed after muscimol in one rat with microinjection sites in the intermediate neostriatum, $\sim 2 \mathrm{~mm}$ from the caudal accumbens shell. However, several other control rats with nearly identical neostriatal sites emitted essentially no defensive treading after muscimol microinjection or vehicle microinjection ( $<10 \mathrm{sec}$ in both cases), so the reason for this control outlier remains unclear.

\section{Conditioned place preference/avoidance}

Muscimol microinjections within the accumbens shell caused conditioned place preference at most rostral sites but conditioned place avoidance at most caudal sites [ANOVA (drug $\times$ region) $F_{(1,73)} 7.15 ; p<0.01$ ) (Fig. 1). Muscimol-conditioned positive place preferences $(>100 \mathrm{sec}$ increase in the muscimol-paired chamber on average) were produced by muscimol microinjection sites located primarily in the most anterior $25 \%$ of the shell, that is, more than $+1.6 \mathrm{~mm}$ anterior to bregma $(n=7$ of 10 sites; mean preference $=33 \%$; ANOVA $\left.F_{(1,19)}=11.20 ; p<0.005\right)$. Each of these rats with far-rostral sites $(>20 \%$ place preference) also met criteria to be positive eaters (Figs. 1, 7, 8). However, most rostral sites $(65 \%)$ between +1.6 and $+1.1 \mathrm{~mm}$ anterior to bregma actually produced muscimol-conditioned place avoidance, instead of preferences, although all still elicited eating behavior. When microinjection sites for individual rats were plotted separately, $48 \%$ of rostral eating sites (those mainly located in the farthest rostral shell) produced at least $20 \%$ conditioned place preference, $38 \%$ of rostral sites produced $10-50 \%$ conditioned place avoidance (most of these sites less rostral than sites that produced place preference, but still in the rostral half of the shell), and $14 \%$ of rostral sites produced no change.

A rostrocaudal gradient for place preference conditioning became even clearer when caudal shell sites were considered, because muscimol caused the strongest negative conditioned place avoidance at sites in the caudal half of the shell, that is, 1.1-0.5 $\mathrm{mm}$ anterior to bregma $\left(F_{(1,73)}=7.15 ; p<0.01\right.$ for strength of muscimol avoidance in rostral versus caudal shell; $p<0.02$ at 15 min; and $p<0.01$ at $30 \mathrm{~min}$ for muscimol versus vehicle avoidance effect in caudal shell) (Fig. 1). The strongest conditioned avoidance $(>25 \%)$ was produced by muscimol at sites caudal to $+1.0 \mathrm{~mm}$ bregma, at points just above and caudal to the islands of Calleja, and roughly above the rostral emergence of the nucleus of the vertical limb diagonal band. All of the rats with these caudal shell sites for place avoidance also met criteria for defensive treading. Conversely, $85 \%$ of caudal defensive treading sites produced at least $>10 \%$ conditioned place avoidance after muscimol, and the remaining $15 \%$ produced no change. No caudal sites produced conditioned place preferences.
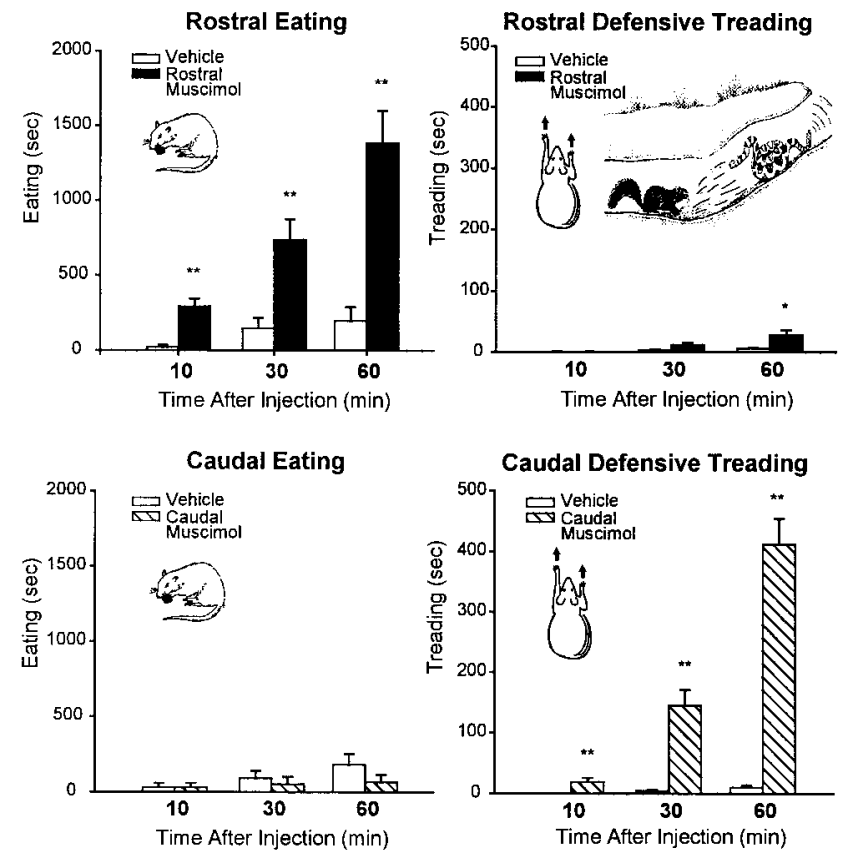

Figure 2. Experiment 2: time spent eating and defensive treading (mean \pm SEM) after vehicle or $75 \mathrm{ng}$ muscimol microinjection. Rostral shell muscimol increased eating behavior immediately and continuously (results in terms of grams of food intake were similar) but elicited minimal defensive treading. Caudal muscimol microinjection elicited robust defensive treading behavior but never increased eating behavior (cumulative over 60 min trial). ${ }^{*} p<<0.001 ;{ }^{*} p<0.05$.

For the entire shell, there was a significant correlation between degree of rostrocaudal placement and degree of conditioned place preference/avoidance $(r=0.35 ; p=0.03)$. Medial shell sites rostral to approximately $+1.6 \mathrm{~mm}$ produced mild place preference, sites between +1.6 and $+1.1 \mathrm{~mm}$ produced mild place avoidance, and sites caudal to +1.1 produced robust place avoidance (Fig. 1).

In summary, muscimol microinjection into the entire rostral half of the shell reliably elicited increased food intake, but only the most far rostral sites also produced conditioned place preference. The majority of muscimol sites in the less extreme rostral half of the medial shell caused a negative conditioned place avoidance, despite increasing appetitive eating behavior. Conversely, muscimol microinjections into the caudal shell uniformly caused both negative conditioned place avoidance and negative defensive treading behavior (while suppressing food intake). Muscimol thus appears to influence place conditioning along a positive-to-negative rostrocaudal gradient within the medial shell, which overlaps roughly but not perfectly with the gradient for eliciting feeding versus fear.

\section{Experiment 2: affective positive/negative taste reactivity versus feeding/fear}

Muscimol-elicited eating behavior and defensive treading behavior.

Rostral shell microinjections increased eating behavior. Food intake was again increased by rostral shell muscimol microinjections by $\sim 500 \%$ over vehicle levels (see Figs. 3, 7, and 8) [ANOVA (drug) $\left.F_{(1,21)}=49.09 ; p<0.001\right)$. Time spent in eating behavior was similarly elevated by $>500 \%$ after rostral shell muscimol at all three time points in the hour after microinjection [10, 30, $60 \mathrm{~min}$; ANOVA (drug) $F_{(1,65)}=49.83 ; p<0.001$ ) (Fig. 2). Only a few 


\section{Rostral Shell: Sucrose Taste Overall Affective Reactions}

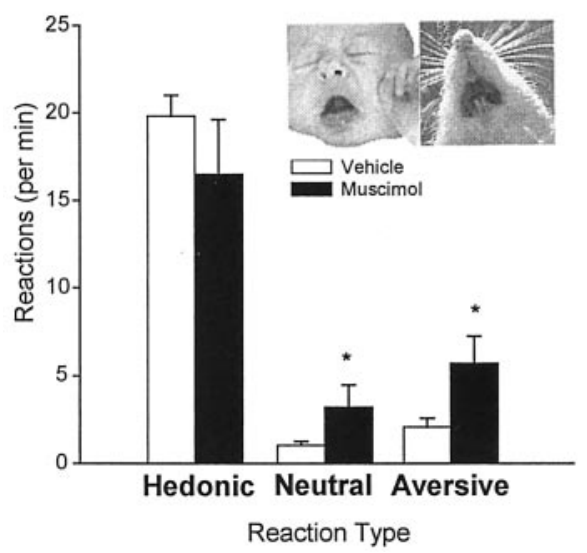

Affective Components

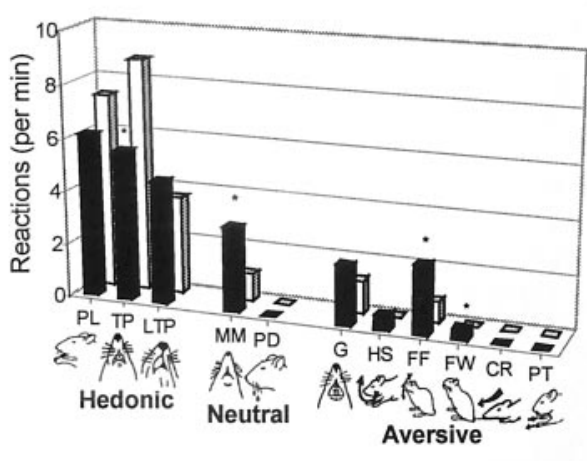

Time Effects

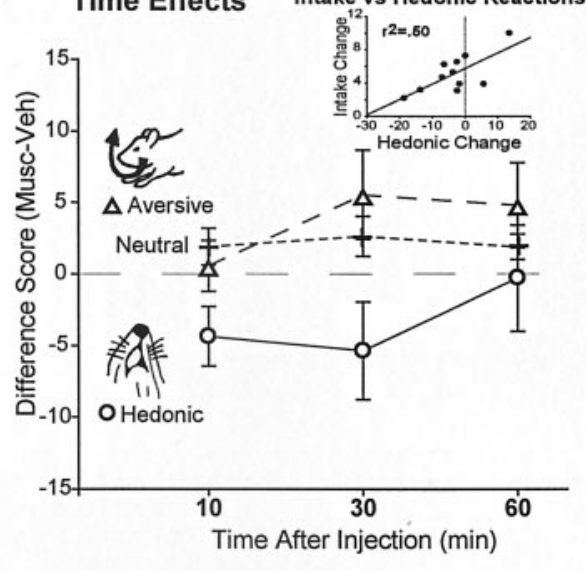

Figure 3. Experiment 2: affective taste reactivity to sucrose inf usions after rostral shell microinjections (mean \pm SEM; number of total hedonic, neutral, and aversive taste reactions). Overall a small shift toward aversive reaction patterns to sucrose taste were produced by rostral shell muscimol microinjections (left bars). For reference purposes, top photographs show prototypical disgust gape expression in human infant and the homologous gape component in adult rat that was measured here [from Steiner et al. (2001) and Berridge (2000)]. Breakdown of affective reaction categories into component facial and body reactions (middle bars): rostral muscimol overall decreased positive tongue protrusions and increased negative forelimb flails and face washing. PL, Paw licking; TP, rhythmic tongue protrusions; $L T P$, lateral tongue protrusions; $M M$, rhythmic mouth movements; $P D$, passive dripping of inf used solution; $G$, gapes; $H S$, head shakes; $F F$, forelimb flails; $F W$, face wash paw strokes; $C R$, chin rubs; $P T$, paw treading. Similar effects occurred for all infusions (right). ${ }^{*} p<0.05$. Correlation between food intake and affective reactions to taste showed a positive relationship between the two muscimol effects, both related to degree of rostrocaudal placement in accumbens shell $(p<0.01$; top inset scatter plot $)$.

seconds of cumulative defensive treading behavior were elicited by rostral muscimol on average [ANOVA (drug) $F_{(1,21)}=8.32$; $p<0.02$ ], and most rats in this group showed no defensive treading at all.

Caudal shell microinjection elicited defensive treading behavior. Caudal shell muscimol again elicited robust defensive treading behavior and tended to decrease food intake rather than increase it. Defensive treading was increased by $>1000 \%$ of vehicle levels (typically eliciting $>400 \mathrm{sec}$ of cumulative treading behavior compared with only $0-5$ sec after vehicle; $F_{(1,24)}=88.75 ; p<$ 0.001] (Fig. 2). Defensive treading was especially high during the second half hour of the $1 \mathrm{hr}$ trial (drug $\times$ time interaction $F_{(2,83)}=91.66 ; p<0.001$; final two periods each $p<0.001$ compared with vehicle).

\section{Rostral muscimol: mixed enhancement/suppression of positive hedonic reactions}

Sucrose infusions. Positive hedonic reactions elicited by the taste of sucrose were increased by $50 \%$ in the two rats that had the most far rostral placements of the rostral group in experiment 2 $[$ mean vehicle $=18.2 \pm 2.8$, muscimol $=27.5 \pm 3.8 ; 51 \%$ enhancement; ANOVA (drug) $F_{(1,11)}=6.35 ; p=0.053$ ] (see Figs. 7,8 ). The largest enhancement of positive hedonic taste reactions was observed in the same rat that also showed the largest increase in food intake. In general, there was a significant correlation between a rat's amount of muscimol-elicited food intake and its change in hedonic reactions to sucrose $\left(r=+0.71 ; r^{2}=0.50 ; p<\right.$ 0.05) (Fig. 3, inset).

All 11 rats with sites in the rostral half of the shell showed robust muscimol-elicited eating behavior, however, and not just the two that met criterion for positive increases in hedonic taste reactivity. Surprisingly, the positive correlation between intake and hedonic change resulted chiefly from muscimol-induced suppression of hedonic reactions to sucrose in rats whose placements were less rostral than approximately $+1.7 \mathrm{~mm}$ anterior to bregma (i.e., not in the most rostral one-fourth of the shell) (Fig. 3, 7, 8).
All rats ate after rostral muscimol microinjections regardless of whether they had hedonic suppression, but those that had the smallest hedonic suppression tended to eat more than those that had larger suppression of positive hedonic reactivity to the sucrose taste. For the entire group with sites in the rostral half of shell, in fact, overall hedonic reactions tended to be suppressed by muscimol (Fig. 3) [one-way ANOVA (drug) $F_{(1,65)}=3.41 ; p=$ $0.07]$. When the two rats that displayed increased hedonic reaction were excluded, the suppression of hedonic reaction by muscimol in rostral shell became significant [ANOVA (drug) $F_{(1,53)}=$ 14.86; $p<0.001]$. Breaking down the positive affective taste reactivity category into separate reactivity components for these rats, rhythmic tongue protrusions were significantly suppressed by shell muscimol during sucrose infusions $(p<0.02)$ (Fig. 3), and paw licking $(p=0.065)$ and lateral tongue protrusions $(p=0.03)$ were significantly suppressed during the $30 \mathrm{sec}$ period immediately after the sucrose infusion in which rats normally still emit a few affective "after-reactions."

By contrast, negative aversive reactions were rarely elicited by sucrose inf usions after vehicle microinjections but were increased by $>200 \%$ after muscimol in rostral shell $\left(F_{(1,65)}=5.45 ; p<\right.$ $0.03)$. As might be expected, no aversive increase was seen in the two rats that had the most rostral microinjection placements, which had instead increased positive hedonic reactions elicited by sucrose. Breaking down the negative aversive affective reaction category into specific component responses elicited by sucrose inf usions, forelimb flails $(p<0.04)$ and face washing $(p=0.06)$ were both increased after muscimol in rostral shell. Similar results were found in each taste reactivity test at all three time points tested (10, 30, and 60 min after microinjection) (Fig. 3) and in reactions both during the infusion and immediately after.

Quinine infusions. Taste reactivity to quinine was also made more negative overall by muscimol microinjections, even in the rostral half of the shell. The effect of muscimol microinjections on reactions to quinine was primarily to further suppress positive 

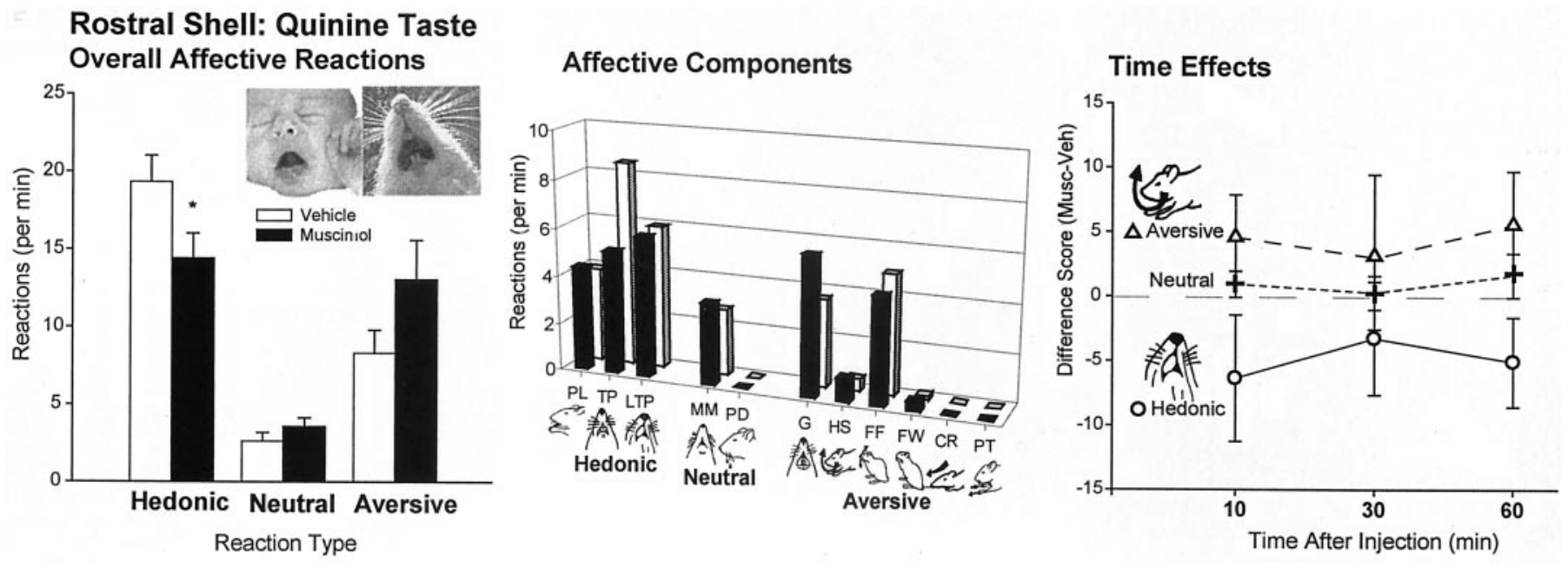

Figure 4. Experiment 2: affective taste reactivity to quinine after rostral shell microinjections (mean \pm SEM reactions). Overall a moderate suppression of positive affective reactions and shift toward increased aversion to quinine taste was produced by rostral muscimol microinjections. Middle bars indicate breakdown of affective reaction categories into component facial and body reactions. Similar effects occurred for all infusions $(b o t t o m)$. ${ }^{*} p<0.05$.
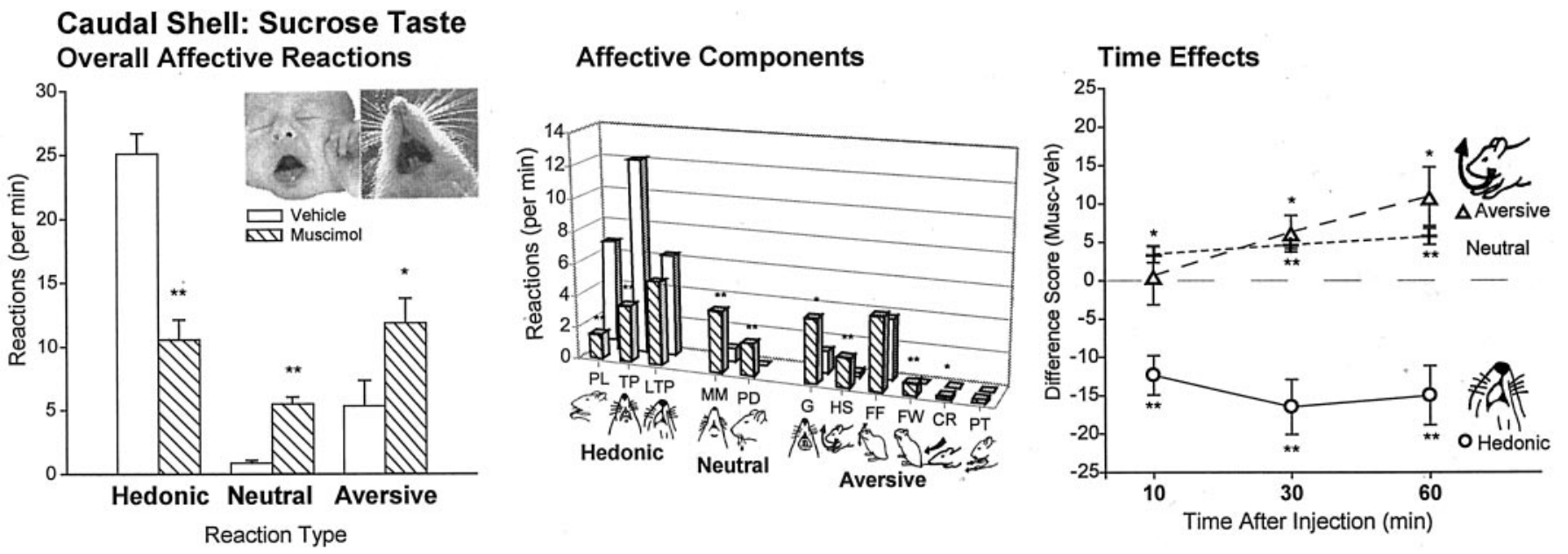

Figure 5. Experiment 2: affective taste reactivity to sucrose after caudal shell microinjections (mean \pm SEM reactions). Caudal shell muscimol strongly shifted affective reactions toward negative aversion and suppressed positive hedonic reactions to sucrose (left). Breakdown of affective reaction categories into component facial and body reactions (middle bars) revealed suppression of positive paw licking and rhythmic tongue protrusions and increased negative gapes, head shakes, face washing, and chin rubs. Similar effects occurred for all inf usions (right). ${ }^{*} p<0.05 ;{ }^{* *} p<0.001$.

reactions [one-way ANOVA (drug) $F_{(1,65)}=4.14 ; p<0.05$ ] and potentiate aversive reactions by roughly $150 \%\left(F_{(1,65)}=3.64 ; p=\right.$ 0.065 ) (Fig. 4), just as it did for reactions to sucrose. Again, an exception to this aversive enhancement was seen in the two rats that had the farthest rostral placements in the anterior $25 \%$ of the shell, which showed no change in aversive reactions after muscimol. When these farthest rostral two rats were excluded from the analysis, the increase in aversion to quinine by muscimol became significant for the rostral group overall $\left(F_{(1,53)}=6.51 ; p<0.02\right)$.

Caudal shell muscimol: negative affective reactions to sucrose and quinine

Hedonic reactions elicited by sucrose were even more suppressed after caudal shell muscimol than after rostral microinjections $\left(F_{(1,148)}=13.74 ; p<0.001\right)$, and negative aversive reactions were even more increased after muscimol in caudal shell than in rostral shell $\left(F_{(1,148)}=11.20 ; p=0.001\right)$. Component hedonic responses suppressed during sucrose inf usions included paw licks and rhythmic tongue protrusions (both $p<0.001$; overall hedonic suppres- sion for caudal shell muscimol versus vehicle, $F_{(1,81)}=26.04 ; p<$ 0.001). Conversely, several aversive component reactions to sucrose were increased by caudal muscimol by $>200 \%$ over vehicle baseline: gapes, headshakes, face washing, and chin rubs (all $p<$ 0.05; overall aversive increase for caudal shell muscimol versus vehicle, $F_{(1,81)}=5.60 ; p<0.03$ ) (Fig. 5).

In response to oral quinine infusions, caudal muscimol similarly increased the already higher number of aversive reactions $>300 \%$ above vehicle levels to the bitter taste [ANOVA (drug) $F_{(1,81)}=8.59 ; p<0.01$ ] (Figs. 6, 7, 8), whereas it suppressed most the level of hedonic reactions to quinine $50 \%$ below vehicle levels $\left(F_{(1,81)}=19.48 ; p<0.001\right)$. Furthermore, the magnitude of aversive enhancement grew over the course of the hour after microinjection [comparing tests at 10, 30, and 60 min ANOVA (interaction of drug $\times$ time) $\left.F_{(2,81)}=3.81 ; p=0.04\right]$. This temporal pattern was true for both sucrose and quinine infusions and for the $30 \mathrm{sec}$ post-inf usion after-reaction periods $\left(F_{(1,81)}=\right.$ 11.78; $p<0.005)$. 

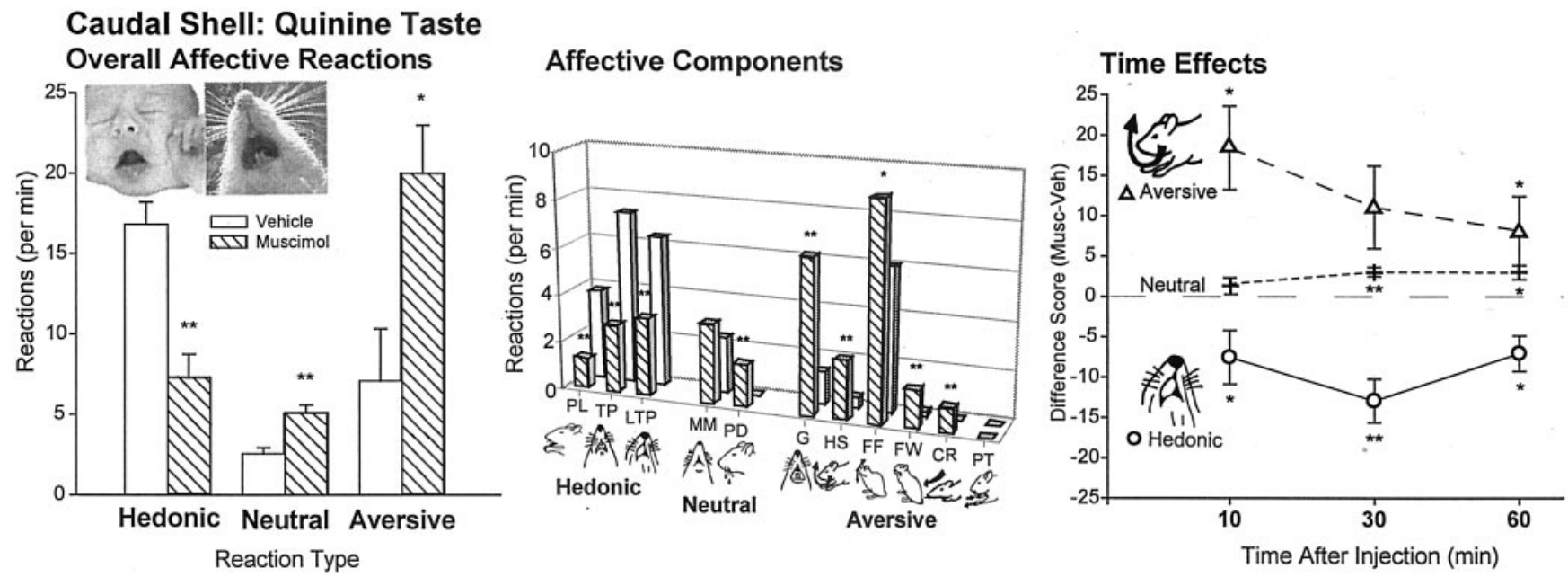

Figure 6. Experiment 2: affective taste reactivity to quinine after caudal shell microinjections (mean \pm SEM reactions). Caudal shell muscimol increased overall negative reactions to quinine (left). Breakdown of affective reaction categories into component facial and body reactions revealed suppression of positive paw licking, rhythmic tongue protrusions, and lateral tongue protrusions, but increased negative gapes, head shakes, forelimb flails, face washing, and chin rubs (middle bars). Similar effects occurred for all infusions (right). ${ }^{*} p<0.05 ;{ }^{* *} p<0.001$.

In conclusion, muscimol microinjection increased both food intake and hedonic reactions to taste in sites at the far rostral region of the shell, although at most rostral sites muscimol increased food intake while actually slightly suppressing hedonic reactions and increasing aversive reactions to tastes. Conversely, muscimol microinjections into caudal shell sites produced both defensive treading behavior and enhanced aversive reactions to both sucrose and quinine tastes. Thus both food intake and affective taste reactions are elicited along positive-to-negative gradients within the medial shell by muscimol. However, these gradients do not perfectly match, because intermediate sites increased positive food intake but suppressed positive hedonic affective reactions to tastes and increased negative aversive reactions.

\section{DISCUSSION}

Activation of $\mathrm{GABA}_{\mathrm{A}}$ receptors in the medial shell of nucleus accumbens triggered multiple motivated behaviors and affective reactions that were organized along bivalent rostrocaudal gradients. Muscimol in the most far rostral $25 \%$ of the shell caused increased eating, positive hedonic taste enhancement, and conditioned place preferences. Less far rostrally, muscimol still elicited robust eating but caused negative affective reactions to taste and conditioned negative place avoidance. Conversely, muscimol at caudal sites suppressed food intake, caused negative affective reactions to the taste of sucrose, caused an associated place to be avoided, and triggered unconditioned fearful behaviors (i.e., defensive treading behavior during eating/treading tests and escape attempts and distress vocalizations after all tests when rats were retrieved by the experimenter).

Notably, no neutral zone was evident, even at intermediate levels of the shell. Instead, some midway sites simultaneously elicited mixed bouts of both positive eating and negative fearful treading, whereas others elicited only one of these valenced behaviors. No sites had zero motivational/affective valence after $\mathrm{GABA}_{\mathrm{A}}$ receptor activation under these conditions.

\section{GABAergic food intake, affect, and hunger}

Several potential explanations could account for eating behavior elicited by rostral GABAergic circuits: natural hunger and palat- ability enhancement, a coping response to stress, or a fragmentary psychological process such as incentive salience. However, several observations indicate against interpretations of either pure natural hunger or pure stress. Eating was accompanied by positive affective reactions at far rostral sites but by negative affective reactions at intermediate rostral sites. Positive affective enhancement of taste "liking" is consistent with the alliesthesia of natural hunger (Cabanac, 1979; Berridge, 1991) but not with a stresscoping hypothesis. Conversely, a natural hunger explanation is incompatible both with the increased negative aversive reactions to taste at intermediate rostral sites and with the conditioned place preference at far rostral sites. Our conclusion that GABAergic eating is not caused by natural hunger is compatible with observations by Baldo et al. (2001) that shell muscimol microinjections fail to enhance operant responding for food.

Alternatively, GABAergic eating behavior might be explained by a fragmentary psychological component of hunger and other natural motivations, such as incentive salience or "wanting." For example, Berridge and colleagues suggest that incentive salience is attributed by mesoaccumbens systems to neural representations of food, drugs, or other reward-related stimuli (Berridge and Valenstein, 1991; Robinson and Berridge, 1993; Berridge and Robinson, 1998; Wyvell and Berridge, 2000). Incentive salience is a component of appetite and reward but does not itself correspond fully to any natural appetite state. In this context, "wanting" would simply mean that rostral muscimol microinjections caused neural representations of the sight and smell of food to be attributed with incentive salience, so that the perceived food became attractive enough to promote avid eating. It does not mean necessarily that food became an instrumental goal or took on any other cognitive or hedonic features of ordinarily wanted incentives (Balleine and Dickinson, 2000; Berridge, 2001).

\section{GABAergic defensive treading, affect, and fear}

Similar to rostral eating and hunger, defensive treading behavior elicited by caudal shell GABAergic receptor activation may not correspond fully to any natural state of fear, although it may involve some motivational components shared with natural fearful states. Defensive treading patterns observed here are similar 

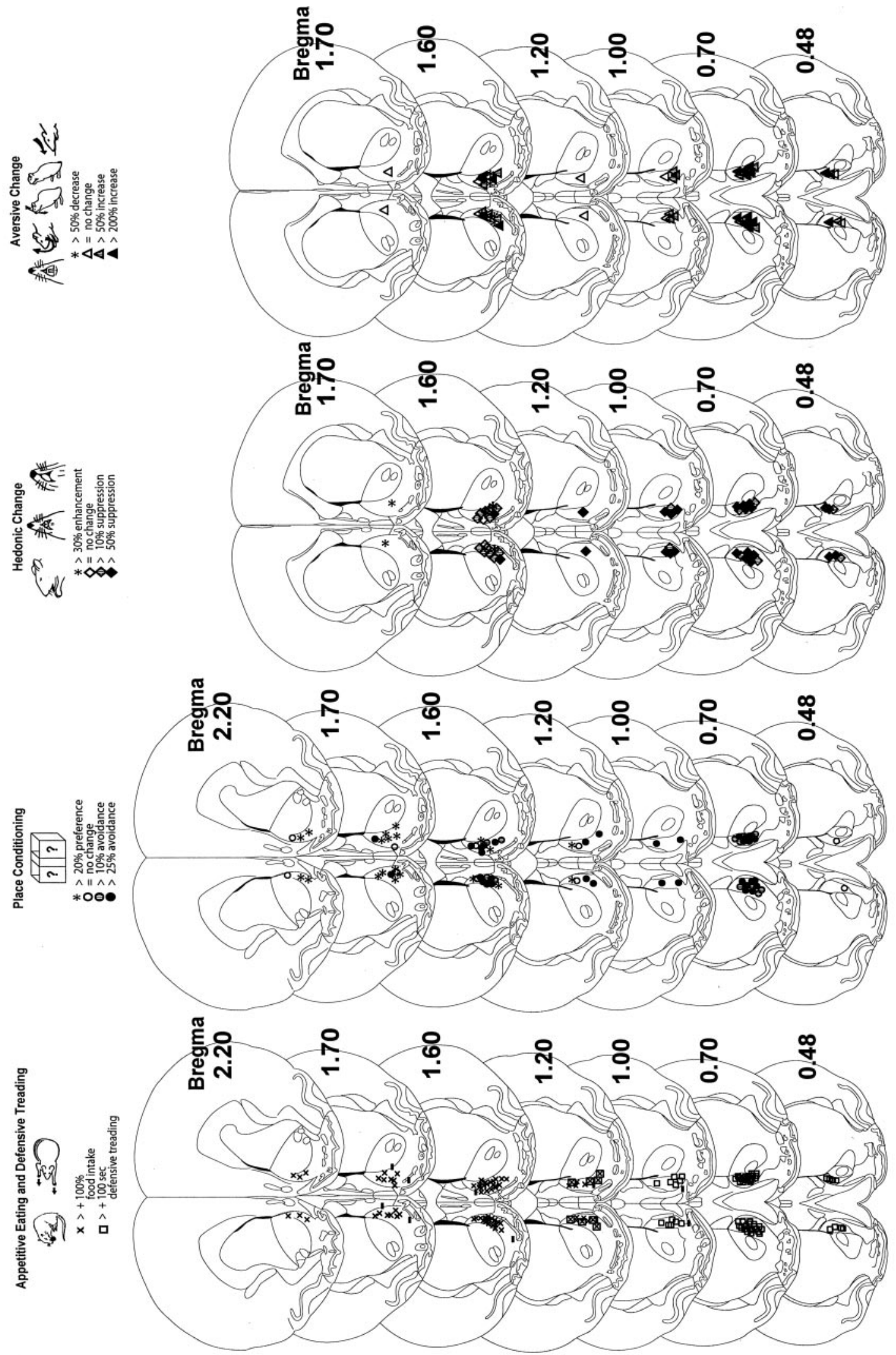

Figure 7. Coronal function maps (experiments 1 and 2). Microinjection sites are plotted for valenced muscimol-elicited effects on eating behavior and defensive treading behavior (left), place preference/avoidance conditioning (second from left), positive affective reactions to sucrose taste (second from right), and negative affective reactions to quinine taste (right). Rostrocaudal gradients of positive-to-negative valence can be observed for all behaviors in medial shell. Several far rostral muscimol microinjections produced positively valenced effects, and caudal microinjections reliably produced negative effects, whereas intermediate sites produced mixed positive effects (eating behavior) and negative effects (conditioned place avoidance and taste aversion). Stereotaxic atlas from Paxinos and Watson (1997). 
A.

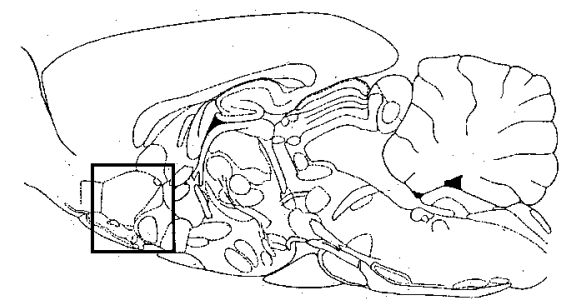

B.
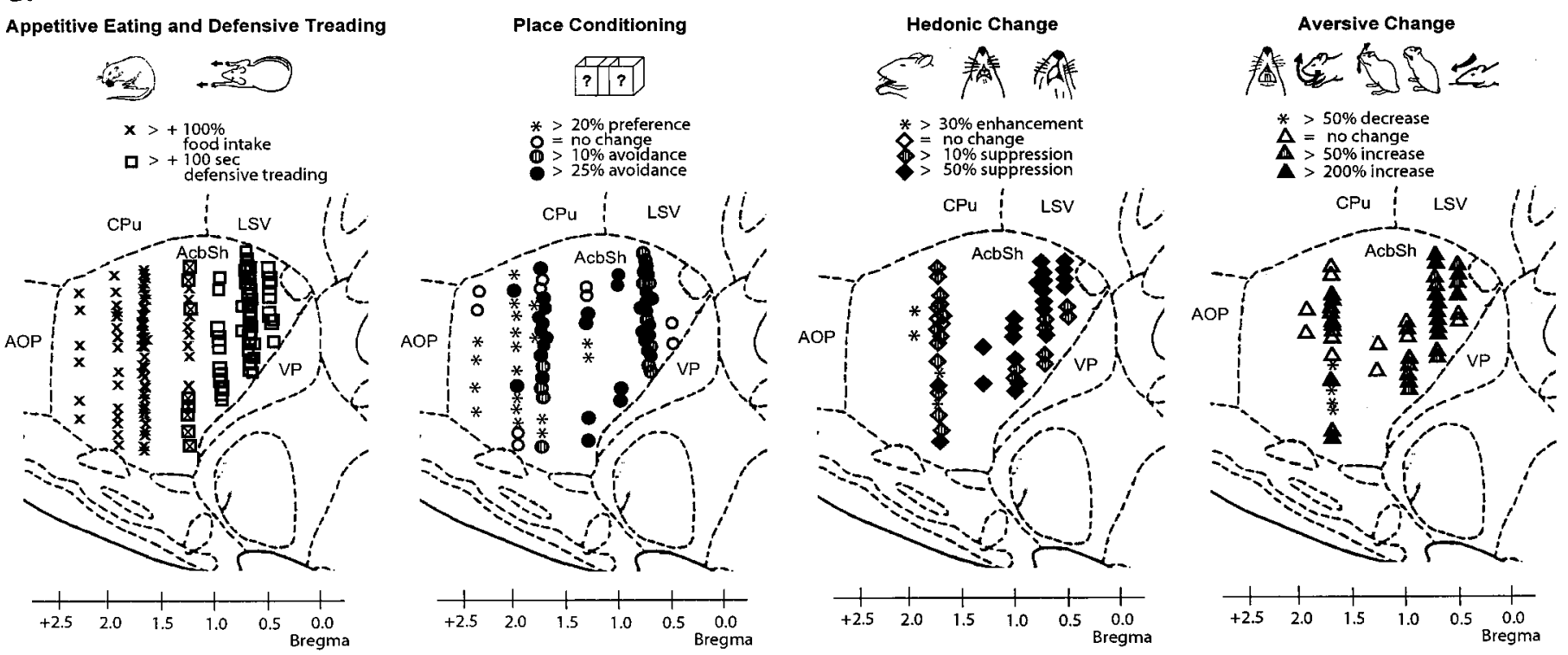

Figure 8. Sagittal function maps (experiments 1 and 2). Microinjection sites are plotted (bilaterally, 2 sites for each rat) for valenced muscimol-elicited effects in sagittal plane ( $0.9 \mathrm{~mm}$ lateral from midline). Rostrocaudal gradients can be observed in medial shell for eating behavior and defensive treading behavior (left), place preference/avoidance conditioning (second from left), positive affective reactions to sucrose taste (second from right), and negative affective reactions to quinine taste (right). Far rostral microinjections produced all positively valenced effects (increased eating behavior, positive enhanced sucrose liking, and reduced quinine disliking, positive conditioned place preference). Caudal injections produced all negatively valenced effects (fearful defensive treading behavior, negative taste disliking, negative conditioned place avoidance). Intermediate sites produced mixed positive results (eating behavior) and negative results (conditioned place avoidance and taste disliking). For all behaviors, both the valence and magnitude of muscimol-induced change correlated with site position along a rostrocaudal gradient. Stereotaxic atlas from Paxinos and Watson (1997).

to the natural anti-predator treading reactions that rats deploy against electrified shock prods, that mice use against scorpions, and that ground squirrels use against rattlesnakes that attack their burrow (Owings and Coss, 1977; Treit et al., 1981; Londei et al., 1998; Owings and Morton, 1998; Reynolds and Berridge, 2001). During defensive treading, rats kick sand against targets and build protective mounds between them, here directed at exposed parts of the test chamber in the absence of actual threats. A fearful interpretation is consistent also with observed distress vocalizations and escape attempts after caudal shell muscimol.

Defensive treading behavior is an active coping form of fearful reaction, clearly different from passive inhibitory freezing, startle, etc. Albeit speculative, a negative valence extension of the mesolimbic hypothesis of incentive salience could provide one possible explanation for observed fear, feeding, and place conditioning patterns (Berridge and Robinson, 1998). By this hypothesis, negative "fearful salience" caused by caudal muscimol microinjections, related to incentive salience but negative in motivational valence, could be attributed to chamber stimuli, thus causing them to grab attention but to become threatening, avoided, and even defended against, rather than attractive. At caudal sites the $\mathrm{GABA}_{\mathrm{A}}$ agonist may bias motivation strongly toward univalent fearful salience, eliciting only negative defense and conditioned avoidance and suppressing appetitive behavior. At intermediate sites the valence of motivational salience may be more ambiguous or flexibly stimulus dependent: the experimenter and open room may still be most readily attributed with negative fearful salience, whereas food may be more likely to become the target of positive incentive salience, and so be eaten. If so, it may be possible to bias the valence of GABA-evoked motivational salience by manipulating external stressors or stimuli related to danger assessment in future studies.

\section{Muscimol-elicited wanting versus liking}

Beyond any fearful process, however, the aversive orofacial expressions to sweet tastes observed after caudal muscimol microinjections indicate a more specifically affective form of negative reaction (Fig. 5). Fear of footshock is not ordinarily accompanied by taste "disliking" expressions (Pelchat et al., 1983), but both negative defense and taste reactions were produced here by caudal shell muscimol. Negative taste reactions included mouth gapes, which in humans have been labeled the prototypical expression of disgust (Rozin, 2000). We stress that taste "liking" and "disliking" here refer solely to these observable behavioral affective reactions, homologous to human affective facial expressions (Berridge, 2000; Steiner et al., 2001), regardless of accom- 
panying subjective states, and is not meant to blur the boundary between objective reaction and subjective experience. Used in this sense, changes in "liking" and "disliking" after muscimol microinjections show that GABAergic neurotransmission in nucleus accumbens is a causal mechanism for determining valence of the brain's behavioral affective reaction to a taste stimulus.

GABAergic effects on taste "liking" and food intake corresponded together at positive rostral and negative caudal ends of the shell. However, affective reactions to taste were dissociated from motivation after intermediate rostral muscimol microinjections, which still caused rats to eat food $>400 \%$ more than normal, but paradoxically to affectively "dislike" sucrose taste. This eating-but-aversive combination appeared similar to previous dissociations of sucrose "wanting" from "liking" caused by mesoaccumbens manipulations (Berridge and Valenstein, 1991; Peciña et al., 1997; Wyvell and Berridge, 2000). However, this is the first dissociation to result from a GABA manipulation, which directly hyperpolarizes medium spiny neurons and their outputs via a mechanism that lies beyond the dopamine synapse.

\section{Neuronal microcircuits in accumbens shell}

The nucleus accumbens has been proposed to contain distinct ensembles of neurons that in principle could function as segregated microcircuits (Pennartz et al., 1994; O’Donnell, 1999). Rostral versus caudal shell subregions appear to receive partially distinct inputs, which might differentially modulate their microcircuits. For example, rostral shell receives denser excitatory projections from dorsal intermediate subiculum, entorhinal cortex, and rostral prelimbic area, whereas the caudal shell receives greater inputs from ventral subiculum, septohippocampal area, basal amygdaloid complex, caudal prelimbic area, and brainstem norepinephrine projections (Phillipson and Griffiths, 1985; Groenewegen et al., 1987; Berendse et al., 1992; Wright et al., 1996; Berridge et al., 1997; Gorelova and Yang, 1997; Totterdell and Meredith, 1997; Groenewegen et al., 1999; Ding et al., 2001). Furthermore, convergence onto single accumbens neurons from hippocampal and amygdaloid inputs occurs chiefly in the caudal and intermediate shell (Mulder et al., 1998). It is possible that muscimol microinjections differentially modulated specific shell microcircuits segregated along the rostrocaudal axis. Such activation of postsynaptic $\mathrm{GABA}_{\mathrm{A}}$ receptors on medium spiny neurons should hyperpolarize these neurons below their ordinary resting potential, diminish periodic "up states," reduce action potentials below their normal low spontaneous firing rates of 1-10 $\mathrm{Hz}$, and disrupt the excitatory impact of cortical and other glutaminergic inputs (Meredith et al., 1993; Pennartz et al., 1994; Kiyatkin and Rebec, 1999; Meredith, 1999; O’Donnell, 1999). Thus muscimol microinjections may have altered processing within some microcircuits while leaving others unaffected.

\section{Rostrocaudal valence gradients: neurochemical/anatomical interaction}

It is important to note that bivalent organization of GABA effects is not a fixed anatomical feature of rostrocaudal microcircuits but rather may reflect specific neurochemical/anatomical interactions. The same anatomical microcircuit may be capable of differently valenced outputs in response to different neurochemical manipulations. For example, dopamine and opioid agonists may have positively valenced motivational effects on behavior, including affective reactions to taste for opioids, even when administered at shell sites that caused negative or mixed effects here (Bakshi and Kelley, 1993; Peciña and Berridge, 2000; Wyvell and Berridge,
2000; Zhang and Kelley, 2000). The reason for such differences may lie in unique neurochemical modulations of synaptic signals by different neurotransmitters. Catecholamine and peptide neurotransmitters may modulate more complexly synaptic hyperpolarization/depolarization than GABA, in ways that interact more dynamically with afferent signals and down/up states of the neuron (O'Donnell and Grace, 1995; $\mathrm{Hu}$ and White, 1997; O’Donnell, 1999). By contrast, glutamate receptor antagonists, which block depolarization of shell neurons, might have functional consequences more similar to muscimol (MaldonadoIrizarry et al., 1995; Kelley and Swanson, 1997; Stratford et al., 1998). Future investigations are needed to clarify such neurochemical/neuroanatomical interactions.

\section{Implications for bivalent human motivation}

The existence of GABAergic rostrocaudal gradients for positive/ negative motivation in accumbens shell may help illuminate how the nucleus accumbens can participate in both appetitive and aversive motivational functions (Salamone, 1994; Gray et al., 1999; Horvitz, 2000). Caudal negative valence might be especially useful in understanding anxiety and related symptoms linked to mesolimbic dysfunction. For example, differential modulation of rostrocaudal accumbens microcircuits by phencyclidine, amphetamine, or related drugs conceivably could contribute to why some chronic users experience symptoms of aversive anxiety or paranoia (Feldman et al., 1997). Similarly, paranoid psychosis symptoms of endogenous schizophrenia in some individuals might be caused partly by selective abnormal recruitment of accumbens microcircuits, causing abnormally valenced affect or motivational salience (Gray et al., 1999; Taylor and Liberzon, 1999; Kapur and Remington, 2001). Finally, it seems possible that selective recruitment of accumbens-related microcircuits, involving bivalent rostrocaudal gradients, might participate in determining normal human affective reactions to reward or distressing events (Becerra et al., 2001; Knutson et al., 2001) and in causing individual differences in the bias of normal positive/negative affective styles (Davidson, 2000).

\section{REFERENCES}

Bakshi VP, Kelley AE (1993) Feeding induced by opioid stimulation of the ventral striatum: role of opiate receptor subtypes. J Pharmacol Exp Ther 265:1253-1260.

Baldo BA, Hanlon EC, Sadeghian K, Kelley AE (2001) Hyperphagia induced by GABA receptor stimulation in the nucleus accumbens shell: is it hunger? Soc Neurosci Abstr 27:422.15.

Balleine BW, Dickinson A (2000) The effect of lesions of the insular cortex on instrumental conditioning: evidence for a role in incentive memory. J Neurosci 20:8954-8964.

Bardo MT, Bevins RA (2000) Conditioned place preference: what does it add to our preclinical understanding of drug reward? Psychopharmacology (Berl) 153:31-43.

Basso AM, Kelley AE (1999) Feeding induced by GABA(A) receptor stimulation within the nucleus accumbens shell: regional mapping and characterization of macronutrient and taste preference. Behav Neurosci 113:324-336.

Becerra L, Breiter HC, Wise R, Gonzalez RG, Borsook D (2001) Reward circuitry activation by noxious thermal stimuli. Neuron 32:927-946.

Berendse HW, Galis-de Graaf Y, Groenewegen HJ (1992) Topographical organization and relationship with ventral striatal compartments of prefrontal corticostriatal projections in the rat. J Comp Neurol 316:314-347.

Berridge KC (1991) Modulation of taste affect by hunger, caloric satiety, and sensory-specific satiety in the rat. Appetite 16:103-120.

Berridge KC (2000) Measuring hedonic impact in animals and infants: microstructure of affective taste reactivity patterns. Neurosci Biobehav Rev 24:173-198.

Berridge KC (2001) Reward learning: reinforcement, incentives, and expectations. In: The psychology of learning and motivation (Medin DL, ed), pp 223-278. New York: Academic.

Berridge KC, Robinson TE (1998) What is the role of dopamine in 
reward: hedonic impact, reward learning, or incentive salience? Brain Res Rev 28:309-369.

Berridge KC, Valenstein ES (1991) What psychological process mediates feeding evoked by electrical stimulation of the lateral hypothalamus? Behav Neurosci 105:3-14.

Berridge KC, Winkielman (2002) What is an unconscious emotion? (The case for unconscious "liking".) Cognit Emotion, in press.

Berridge CW, Stratford TL, Foote SL, Kelley AE (1997) Distribution of dopamine beta-hydroxylase-like immunoreactive fibers within the shell subregion of the nucleus accumbens. Synapse 27:230-241.

Berridge CW, Mitton E, Clark W, Roth RH (1999) Engagement in a non-escape (displacement) behavior elicits a selective and lateralized suppression of frontal cortical dopaminergic utilization in stress. Synapse 32:187-197.

Bolles R (1970) Species-specific defense reactions and avoidance learning. Psychol Rev 77:32-48.

Cabanac M (1979) Sensory pleasure. Q Rev Biol 54:1-29.

Cromwell HC, Berridge KC (1993) Where does damage lead to enhanced food aversion: the ventral pallidum/substantia innominata or lateral hypothalamus? Brain Res 624:1-10.

Davidson RJ (2000) The functional neuroanatomy of affective style. In: Cognitive neuroscience of emotion (Lane RD, Nadel L, eds), pp 371-388. New York: Oxford UP.

Ding DC, Gabbott PL, Totterdell S (2001) Differences in the laminar origin of projections from the medial prefrontal cortex to the nucleus accumbens shell and core regions in the rat. Brain Res 917:81-89.

Feldman RS, Meyer JS, Quenzer LF (1997) Principles of neuropsychopharmacology. Sunderland, MA: Sinauer.

Fujiyama F, Fritschy JM, Stephenson FA, Bolam JP (2000) Synaptic localization of $\mathrm{GABA}(\mathrm{A})$ receptor subunits in the striatum of the rat. J Comp Neurol 416:158-172.

Gorelova N, Yang CR (1997) The course of neural projection from the prefrontal cortex to the nucleus accumbens in the rat. Neuroscience 76:689-706.

Gray JA, Kumari V, Lawrence N, Young AMJ (1999) Functions of the dopaminergic innervation of the nucleus accumbens. Psychobiology 27:225-235.

Grill HJ, Norgren R (1978) The taste reactivity test. I. Mimetic responses to gustatory stimuli in neurologically normal rats. Brain Res 143:263-279.

Grill HJ, Roitman MF, Kaplan JM (1996) A new taste reactivity analysis of the integration of taste and physiological state information. Am J Physiol 271:R677-687.

Groenewegen HJ, Vermeulen-Van der Zee E, te Kortschot A, Witter MP (1987) Organization of the projections from the subiculum to the ventral striatum in the rat. A study using anterograde transport of Phaseolus vulgaris leucoagglutinin. Neuroscience 23:103-120.

Groenewegen HJ, Mulder AB, Beijer AV, Wright CI, Lopes da Silva FH, Pennartz CM (1999) Hippocampal and amygdaloid interactions in the nucleus accumbens. Psychobiology 27:149-164.

Horvitz JC (2000) Mesolimbocortical and nigrostriatal dopamine responses to salient non-reward events. Neuroscience 96:651-656.

Hu XT, White FJ (1997) Dopamine enhances glutamate-induced excitation of rat striatal neurons by cooperative activation of D1 and D2 class receptors. Neurosci Lett 224:61-65.

Kapur S, Remington G (2001) Atypical antipsychotics: new directions and new challenges in the treatment of schizophrenia. Annu Rev Med 52:503-517.

Kelley AE (1999) Neural integrative activities of nucleus accumbens subregions in relation to learning and motivation. Psychobiology 27:198-213.

Kelley AE, Swanson CJ (1997) Feeding induced by blockade of AMPA and kainate receptors within the ventral striatum: a microinfusion mapping study. Behav Brain Res 89:107-113.

Kiyatkin EA, Rebec GV (1999) Modulation of striatal neuronal activity by glutamate and GABA: iontophoresis in awake, unrestrained rats. Brain Res 822:88-106.

Knutson B, Adams CM, Fong GW, Hommer D (2001) Anticipation of increasing monetary reward selectively recruits nucleus accumbens. J Neurosci 21:RC159(1-5).

Koob GF, Bloom FE (1988) Cellular and molecular mechanisms of drug dependence. Science 242:715-723.

Liao RM, Chang YH, Wang SH, Lan CH (2000) Distinct accumbal subareas are involved in place conditioning of amphetamine and cocaine. Life Sci 67:2033-2043.

Londei T, Valentini AM, Leone VG (1998) Investigative burying by laboratory mice may involve non-functional, compulsive, behaviour. Behav Brain Res 94:249-254.

Maldonado-Irizarry CS, Swanson CJ, Kelley AE (1995) Glutamate receptors in the nucleus accumbens shell control feeding behavior via the lateral hypothalamus. J Neurosci 15:6779-6788.
McBride WJ, Murphy JM, Ikemoto S (1999) Localization of brain reinforcement mechanisms: intracranial self-administration and intracranial place-conditioning studies. Behav Brain Res 101:129-152.

Meredith GE (1999) The synaptic framework for chemical signaling in nucleus accumbens. Ann NY Acad Sci 877:140-156.

Meredith GE, Pennartz CM, Groenewegen HJ (1993) The cellular framework for chemical signalling in the nucleus accumbens. Prog Brain Res 99:3-24.

Mulder AB, Hodenpijl MG, Lopes da Silva FH (1998) Electrophysiology of the hippocampal and amygdaloid projections to the nucleus accumbens of the rat: convergence, segregation, and interaction of inputs. J Neurosci 18:5095-5102.

O’Donnell P (1999) Ensemble coding in the nucleus accumbens. Psychobiology 27:187-197.

O’Donnell P, Grace AA (1995) Synaptic interactions among excitatory afferents to nucleus accumbens neurons: hippocampal gating of prefrontal cortical input. J Neurosci 15:3622-3639.

Owings DH, Coss RG (1977) Snake mobbing by California ground squirrels: adaptive variation and ontogeny. Behaviour 62:50-69.

Owings DH, Morton ES (1998) Animal vocal communication: a new approach. New York: Cambridge UP.

Paxinos G, Watson C (1997) The rat brain in stereotaxic coordinates, Ed 3. San Diego: Academic.

Peciña S, Berridge KC (2000) Opioid eating site in accumbens shell mediates food intake and hedonic "liking": map based on microinjection Fos plumes. Brain Res 863:71-86.

Peciña S, Berridge KC, Parker LA (1997) Pimozide does not shift palatability: separation of anhedonia from sensorimotor suppression by taste reactivity. Pharmacol Biochem Behav 58:801-811.

Pelchat ML, Grill HJ, Rozin P, Jacobs J (1983) Quality of acquired responses to tastes by Rattus norvegicus depends on type of associated discomfort. J Comp Psychol 97:140-153.

Pennartz CM, Groenewegen HJ, Lopes da Silva FH (1994) The nucleus accumbens as a complex of functionally distinct neuronal ensembles: an integration of behavioural, electrophysiological and anatomical data. Prog Neurobiol 42:719-761.

Phillipson OT, Griffiths AC (1985) The topographic order of inputs to nucleus accumbens in the rat. Neuroscience 16:275-296.

Reynolds SM, Berridge KC (2001) Fear and feeding in the nucleus accumbens shell: rostrocaudal segregation of GABA-elicited defensive behavior versus eating behavior. J Neurosci 21:3261-3270.

Robinson TE, Berridge KC (1993) The neural basis of drug craving: an incentive-sensitization theory of addiction. Brain Res Rev 18:247-291.

Rozin P (2000) Disgust. In: Handbook of emotions (Lewis M, HavilandJones JM, eds), pp 637-653. New York: Guilford.

Salamone JD (1994) The involvement of nucleus accumbens dopamine in appetitive and aversive motivation. Behav Brain Res 61:117-133.

Schwarzer C, Berresheim U, Pirker S, Wieselthaler A, Fuchs K, Sieghart W, Sperk G (2001) Distribution of the major gamma-aminobutyric $\operatorname{acid}(\mathrm{A})$ receptor subunits in the basal ganglia and associated limbic brain areas of the adult rat. J Comp Neurol 433:526-549.

Shippenberg TS, Bals-Kubik R, Huber A, Herz A (1991) Neuroanatomical substrates mediating the aversive effects of $\mathrm{D}-1$ dopamine receptor antagonists. Psychopharmacology 103:209-214.

Soderpalm AH, Berridge KC (2000) The hedonic impact and intake of food are increased by midazolam microinjection in the parabrachial nucleus. Brain Res 877:288-297.

Spyraki C, Kazandjian A, Varonos D (1985) Diazepam-induced place preference conditioning: appetitive and antiaversive properties. Psychopharmacology 87:225-232.

Steiner JE (1973) The gustofacial response: observation on normal and anencephalic newborn infants. Symp Oral Sens Percept 4:254-278.

Steiner JE, Glaser D, Hawilo ME, Berridge KC (2001) Comparative expression of hedonic impact: affective reactions to taste by human infants and other primates. Neurosci Biobehav Rev 25:53-74.

Stratford TR, Kelley AE (1997) GABA in the nucleus accumbens shell participates in the central regulation of feeding behavior. J Neurosci 17:4434-4440.

Stratford TR, Swanson CJ, Kelley A (1998) Specific changes in food intake elicited by blockade or activation of glutamate receptors in the nucleus accumbens shell. Behav Brain Res 93:43-50.

Taylor SF, Liberzon I (1999) Paying attention to emotion in schizophrenia. Br J Psychiatry 174:6-8.

Totterdell S, Meredith GE (1997) Topographical organization of projections from the entorhinal cortex to the striatum of the rat. Neuroscience 78:715-729.

Treit D, Pinel JP, Fibiger HC (1981) Conditioned defensive burying: a new paradigm for the study of anxiolytic agents. Pharmacol Biochem Behav 15:619-626.

Tzschentke TM (1998) Measuring reward with the conditioned place 
preference paradigm: a comprehensive review of drug effects, recent progress and new issues. Prog Neurobiol 56:613-672.

Waldvogel HJ, Kubota Y, Trevallyan SC, Kawaguchi Y, Fritschy JM, Mohler H, Faull RL (1997) The morphological and chemical characteristics of striatal neurons immunoreactive for the alpha1-subunit of the GABA $(\mathrm{A})$ receptor in the rat. Neuroscience 80:775-792.

Waldvogel HJ, Fritschy JM, Mohler H, Faull RL (1998) GABA(A) receptors in the primate basal ganglia: an autoradiographic and a light and electron microscopic immunohistochemical study of the alpha1 and beta2, 3 subunits in the baboon brain. J Comp Neurol 397:297-325.

Wilkie DM, MacLennan AJ, Pinel JP (1979) Rat defensive behavior: burying noxious food. J Exp Anal Behav 31:299-306.
Wise RA (1998) Drug-activation of brain reward pathways. Drug Alcohol Depend 51:13-22.

Wright CI, Beijer AV, Groenewegen HJ (1996) Basal amygdaloid complex afferents to the rat nucleus accumbens are compartmentally organized. J Neurosci 16:1877-1893.

Wyvell CL, Berridge KC (2000) Intra-accumbens amphetamine increases the conditioned incentive salience of sucrose reward: enhancement of reward "wanting" without enhanced "liking" or response reinforcement. J Neurosci 20:8122-8130.

Zhang M, Kelley AE (2000) Enhanced intake of high-fat food following striatal mu-opioid stimulation: microinjection mapping and fos expression. Neuroscience 99:267-277. 